\title{
The Effect of Solar Irradiance on the Power Quality Behaviour of Grid Connected Photovoltaic Systems
}

\author{
*Minas Patsalides ${ }^{1}$, Demetres Evagorou ${ }^{1}$, George Makrides ${ }^{1}$, \\ Zenon Achillides ${ }^{1}$, George E. Georghiou ${ }^{1,}$ \\ Andreas Stavrou ${ }^{2}$, Venizelos Efthimiou ${ }^{2}$, \\ Bastian Zinsser ${ }^{3}$, Wolfgang Schmitt ${ }^{3}$ and Jürgen H. Werner ${ }^{3}$ \\ ${ }^{1}$ Department of Electrical and Computer Engineering, University of Cyprus \\ 75 Kallipoleos Avenue, P.O. Box 20537 Nicosia, 1678, Cyprus \\ Phone: + 357 22892272, Fax: + 35722892260 \\ e-mail: ee03pm1@ucy.ac.cy, eep5de01@ucy.ac.cy, eep5mg1@ucy.ac.cy, z.achillides@cytanet.com.cy, \\ geg@ucy.ac.cy \\ ${ }^{2}$ Electricity Authority of Cyprus \\ Amfipoleos 11, 2025, Nicosia, Cyprus \\ Phone: +35724204058 \\ e-mail : astavrou@eac.com.cy, vefthimi@eac.com.cy \\ ${ }^{3}$ Institut für Physikalische Elektronik \\ Pfaffenwaldring 47, D-70569 Stuttgart, Germany \\ e-mail: bastian.zinsser@ipe.uni-stuttgart.de, wolfgang.schmitt@ipe.uni-stuttgart.de, \\ Juergen.Werner@ipe.uni-stuttgart.de
}

\begin{abstract}
Photovoltaic systems have been increasingly used in the generation of electrical energy, either as a means of providing electricity in areas where there is no grid connection (stand alone systems), or by providing electricity to the grid (grid connected systems). In a deregulated energy market, the cost of energy produced from fossil fuels is rising and the photovoltaic energy becomes a promising alternative source. Yet it still suffers from problems that need to be resolved in order to be widely accepted as an equivalent alternative to fossil fuels. Firstly the more direct problem of efficiency and cost needs to be overcome and secondly the indirect problem of the quality of power provided by photovoltaic technology has to be addressed. In this work 14 different grid connected PV systems have been considered and power quality measurements have been taken. Results for low and average irradiance cases are presented and analyzed in order to determine how power quality quantities are affected by changes in solar irradiance.
\end{abstract}

\section{Keywords}

Power quality, photovoltaic systems, solar irradiance, fluctuations and harmonics

\section{Introduction}

Photovoltaic technology provides an attractive method of power generation and meets the criteria of clean energy and sustainability [1]-[4]. Advanced research is still in progress to increase the efficiency of photovoltaic cells and optimize the production of energy through minimization of power losses and better utilization of incident solar irradiance [5]. The efficiency and proper operation of photovoltaic systems depends on a number of factors. Environmental conditions as well as system design constitute the most important factors in the operation of the PV systems and these can have a significant impact on the efficiency and power quality response of the whole system [6]-[8]. The variable power flow due to the fluctuation of solar irradiance, temperature and choice of power semiconductor devices are some of the parameters that affect the power quality of photovoltaic systems. Good power quality translates into obtaining a sinusoidal voltage and current output from a photovoltaic system in order to avoid harmonics, interharmonics and eventually voltage distortion.

With high connection densities of photovoltaics in the distribution grid, low irradiance can lead to undesirable variations of power and supply quality (voltage and current) at the connection point which might even exceed acceptable limits that are set out by the respective grid codes. Aspects related to the quality of electricity as generated from the inverter, which is the element in a PV system responsible for converting the dc power to ac, are also important. The circuit topology of the inverter can determine the behaviour and the power characteristics, during input and output changes. In addition, large quantities of photovoltaic inverters can give rise to power quality problems on lowvoltage networks, even when inverters comply with

\footnotetext{
* Corresponding Author
} 
standards [9]. Such behaviour, characterized by low power quality, is often troublesome because it prevents reliable equipment operation and causes failure of sensitive electronic devices [10], [11].

In this work, the power quality behaviour of grid connected PV systems has been investigated. The PV site under test comprises of 12 fixed mounted flat-plate, one two axis tracked flat plate and one two-axis tracked concentrating PV system, all of nominal power $1 \mathrm{kWp}$, installed at the University of Cyprus. The technologies involved range from monocrystalline and polycrystalline silicon to amorphous thin film silicon, cadmium telluride (CdTe), Copper Indium Diselenide (CIS), HIT-cell and other solar cell technologies from a wide range of manufacturers. The systems are equally distributed through the three phases, connected to the grid, providing a $14 \mathrm{kWp}$ three phase arrangement.

The purpose of this paper is to present and evaluate measurements based on power quality quantities obtained from the PV site. The power quality parameters measured are complex, active and reactive power, current and voltage harmonics and power factor. The total harmonic distortion (THD) for the voltage and current has also been measured as well, over a period of two weeks. The analysis of measurements revealed high current total harmonic distortion during low solar irradiance conditions. The power factor has also been found to sometimes exceed the acceptable limits, causing high quantities of reactive power to be supplied to the distribution network.

\section{Topology of system under test}

In this work $14 \mathrm{PV}$ systems have been tested which analytically include 12 fixed mounted flat-plate, one two axis tracked flat plate and one two-axis tracked concentrating PV system. The systems are equally distributed through the three phases, connected to the grid, providing a $14 \mathrm{kWp}$ three phase arrangement. The combination of weather data like global irradiation and ambient temperature together with the operating parameters of the 14 systems allows a complete picture regarding their yield performance, degradation and loss mechanisms to be developed. Solar irradiance data from the sophisticated sensor network installed on location have also been obtained. The system configuration is shown in Fig. 1.

\section{Standards for PV grid-connected systems}

Various factors must be considered when designing and installing a photovoltaic system to a distribution network. Guidance regarding the operation and the equipment necessary to ensure compatible operation of photovoltaic systems and distribution networks can be found in IEEE standard 929-2000 "Recommended practice for utility interface of photovoltaic systems". This specific IEEE standard contains information and restrictions for personnel safety, utility system operation, equipment protection and power quality.

The IEEE Standard 519-1992 "Recommended Practices and Requirements for Harmonic Control in Electrical Power Systems" specifies the limits of harmonic voltage and current at the point of common coupling between end user and distribution utilities. The approach adopted in this standard requires the participation of both end users and utilities. The limits established by this standard are equal to $5 \%$ for the voltage and current total harmonic distortion that the producer can provide to the customer. The limits for the maximum individual harmonic components are also determined and must be $3 \%$ for voltage lower than $69 \mathrm{kV}$.

\section{Power grid connection of PV-systems at the University of Cyprus (project PV-yield)}

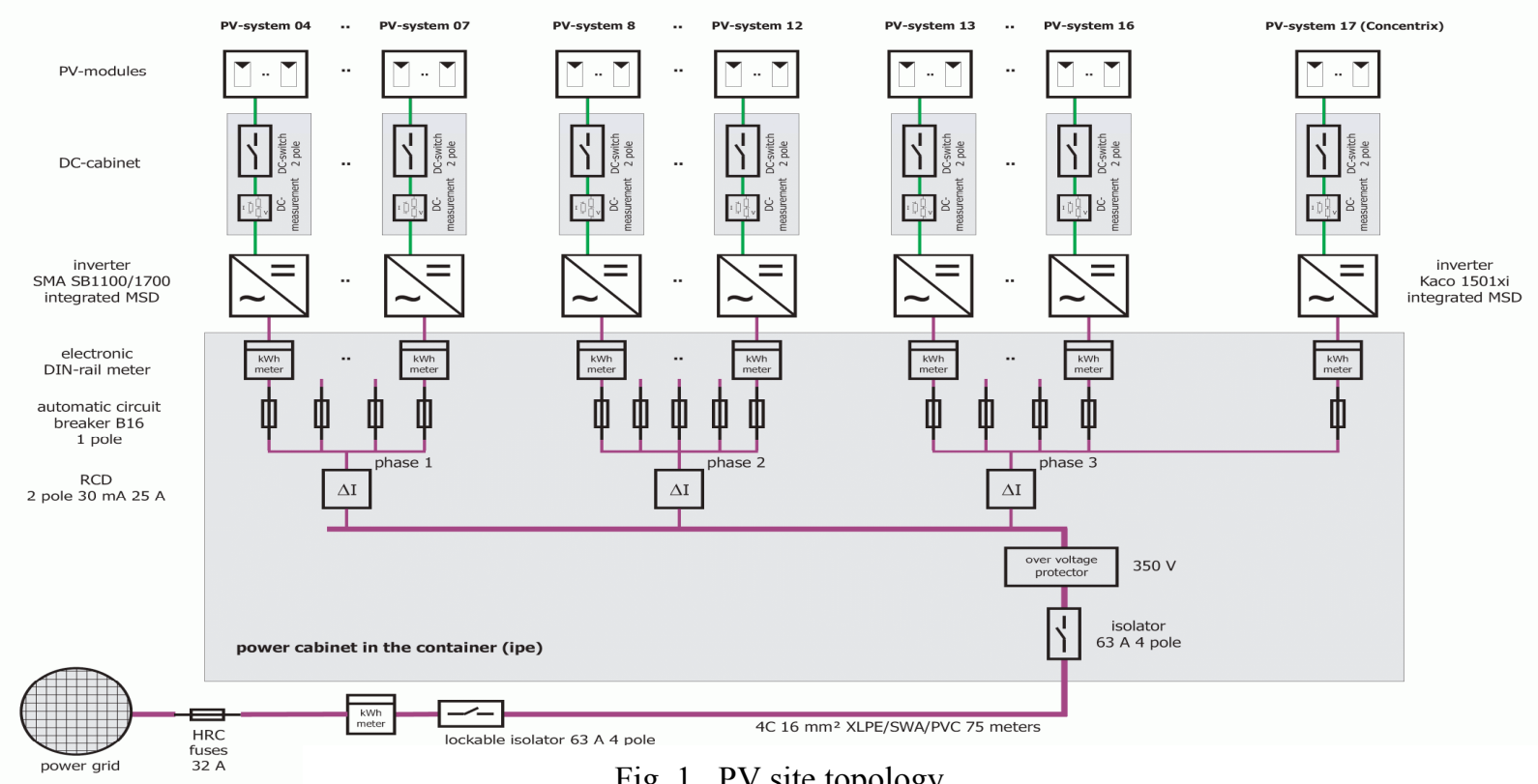


According to the European standard EN50160 (IEC 50160), accommodated by most European Grid Codes, "Voltage characteristics of electricity supplied by public distribution systems", the limit for total harmonic distortion should not exceed $8 \%$, including up to the $40^{\text {th }}$ harmonic.

The European standard EN 61727 (IEC 61727) "Photovoltaic (PV) systems - Characteristics of utility interface" has established more restrictive limits for voltage and current harmonics. The limits proposed for harmonics are $2 \%$ for total voltage harmonic distortion and $5 \%$ for total current distortion. The maximum for individual voltage harmonics is also limited and must not exceed $1 \%$ [12]-[14].

\section{Results and discussion}

Power quality parameters have been measured at the output of the PV site and correlated to the solar irradiance data obtained from the same site. The power quality parameters recorded are the complex power, active power, reactive power, voltage and current for each harmonic frequency. The power factor and total harmonic distortion for voltage and current have been measured as well over a period of two weeks. The solar irradiance incident on the PV modules was also measured for the test period. Two cases of "low" and "average" irradiance have been extracted from the two week measurement data and the results are presented below.

A typical example of the solar irradiance measurements for an average day in December in Cyprus is shown in Fig. 2(a). The active power produced by the system, shown in Fig. 2(b), is strongly dependent on solar irradiance. Fluctuations of solar irradiance lead to fluctuations of active power supplied to the distribution network. The unpredictable response of the system, assuming high densities of photovoltaic systems connected to the distribution network, can be troublesome for the producer of energy that has already scheduled the load for the time of peak demand. In the case of unpredictable variations of power quantities in distribution networks prediction algorithms must be utilized as described in [15]. As seen from Fig. 2(c) the results for the power factor are found to be acceptable for a large fraction of the day, but it can also be observed that the power factor falls below acceptable limits during the time of low solar irradiance. The reactive power as shown in Fig. 2(d) varies significantly, during the day. The lack of proper control to maintain the reactive power within small range limits can cause various problems to the operation of the distribution network, which is based on the concept of unity power factor, meaning that only a small fraction of reactive power is supplied by the central power generator. The reactive power consumed by loads connected to the distribution network is mostly supplied by high voltage cables and capacitors installed on nearby buses of the medium voltage grid. Fast variations of reactive power supplied by photovoltaic systems, assuming very high densities of such systems, can cause fast capacitor switching. Due to this, voltage transients and oscillations can occur with unpredictable amplitude and duration. Transients can lead to failure of sensitive electronic equipment or minimization of the life expectancy of network elements, if the amplitude of a transient exceeds certain limits. Thus it is desirable to reduce the existence of such transients. Modern intelligent inverter designs are now beginning to consider the issue of the control of the reactive power by providing better compensation based on system parameters and the needs of the distribution network.

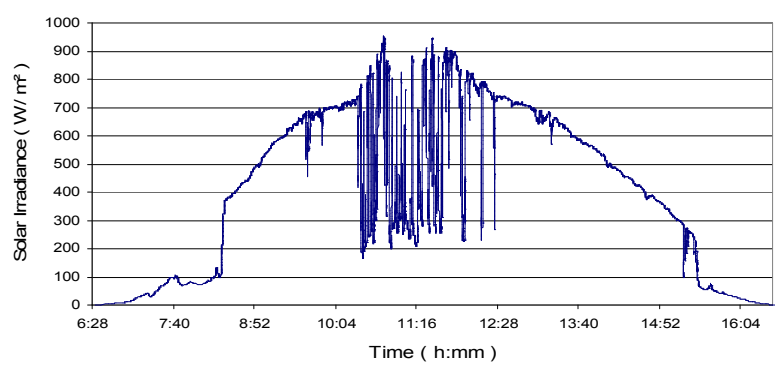

Fig. 2(a). Solar Irradiance observed for an average day

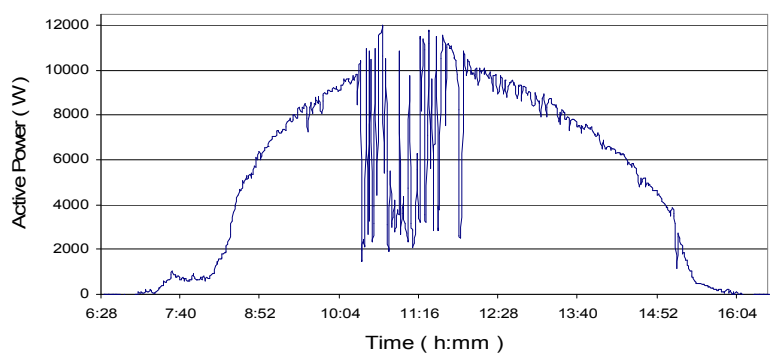

Fig. 2(b). Active Power produced for an average day

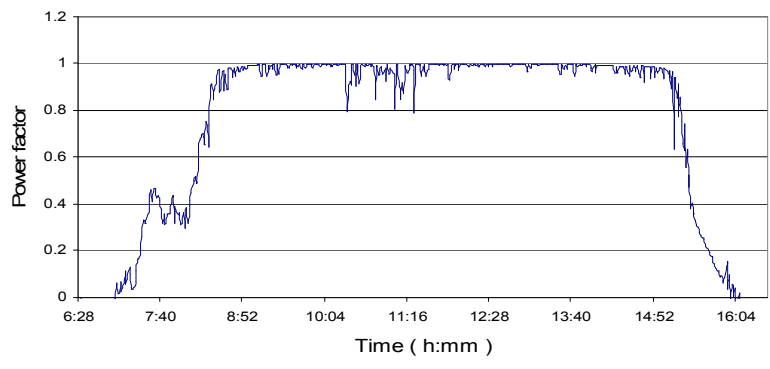

Fig. 2(c). Power Factor measured for an average day

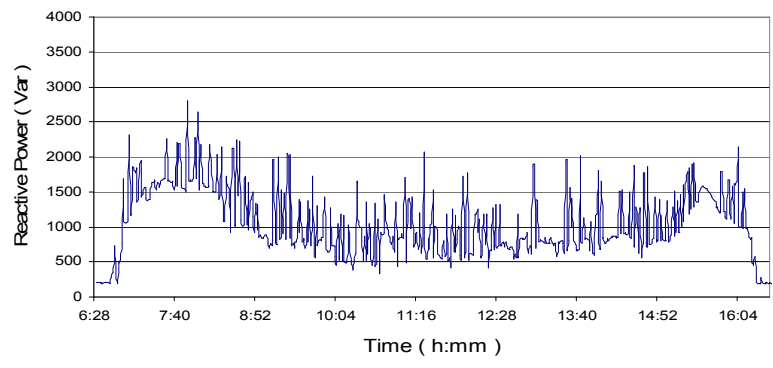

Fig. 2(d). Reactive Power produced for an average day 


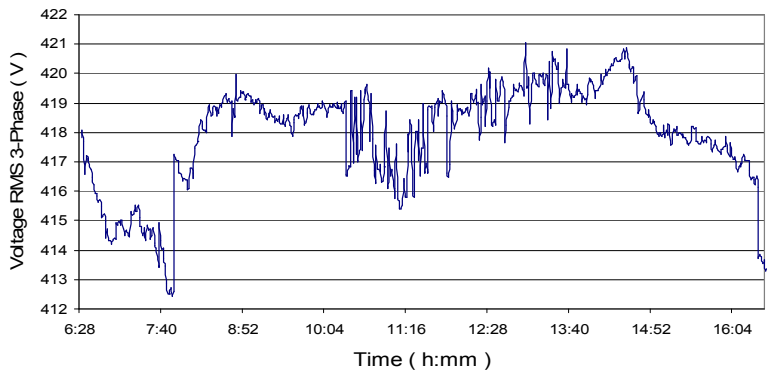

Fig. 2(e). RMS Voltage (3-Phase) measured for an average day

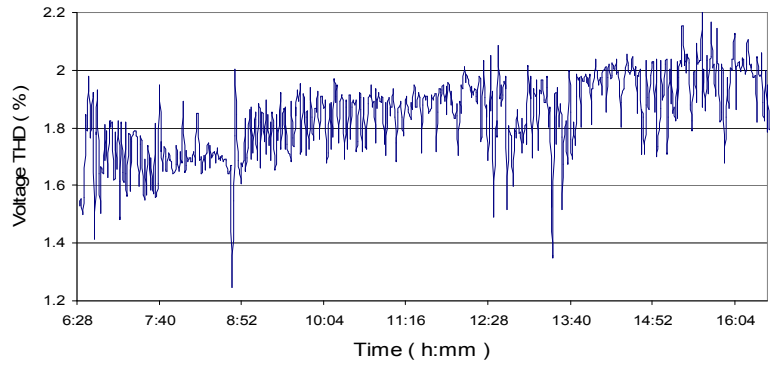

Fig. 2(f). Voltage THD measured for an average day

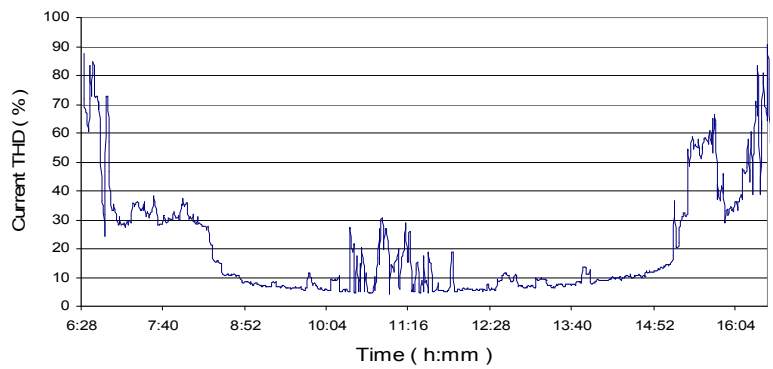

Fig. 2(g). Current THD measured for an average day

Fig. 2. Power Quality Measurements for a day with average solar irradiance

It is very important to recognize, however, that the reactive power produced by such a PV system of nominal peak power $14 \mathrm{kWp}$ is in the range of $1000-2000 \mathrm{Var}$, which is comparable to the reactive power consumption of a host of domestic appliances. The RMS voltage (3-Phase) has small range limits as shown in Fig. 2(e), indicating low dependence on solar irradiance. Voltage and current THD are shown in Fig. 2(f) and Fig. 2(g) respectively. As can be seen the voltage THD lies in the range of $1.2-2.2 \%$, whereas the current THD increases significantly at low solar irradiance conditions reaching a value of $80 \%$ at some instances.

The second case examined is the low irradiance one. Power quality quantities were measured and the results are shown in Fig. 3(a) to 3(g).

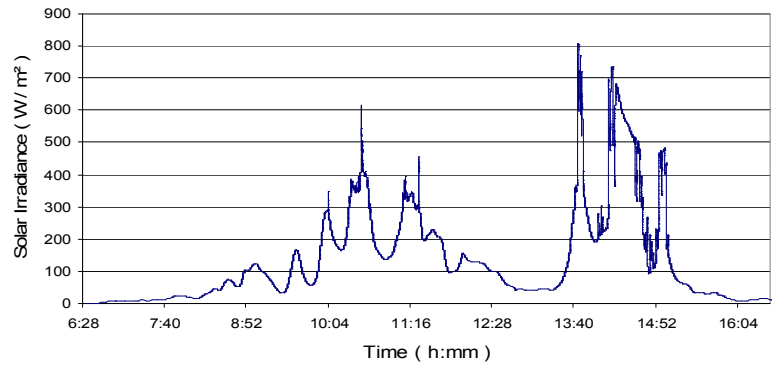

Fig. 3(a). Solar Irradiance observed for a low solar irradiance day

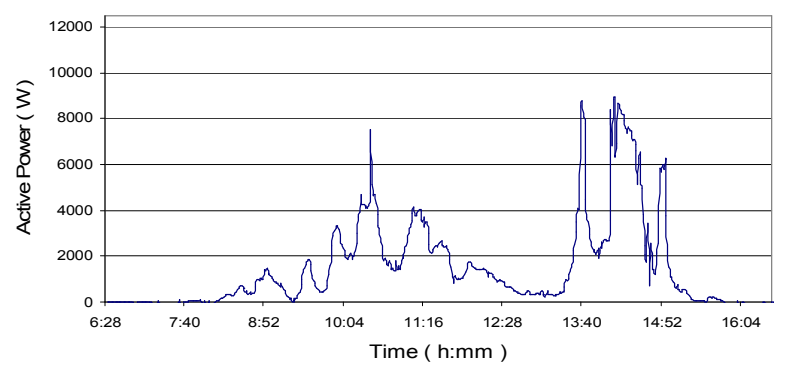

Fig. 3(b). Active Power produced for a low solar irradiance day

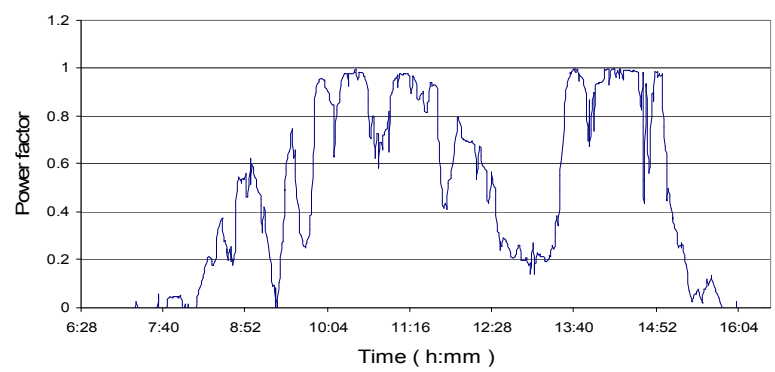

Fig. 3(c). Power Factor measured for a low solar irradiance day

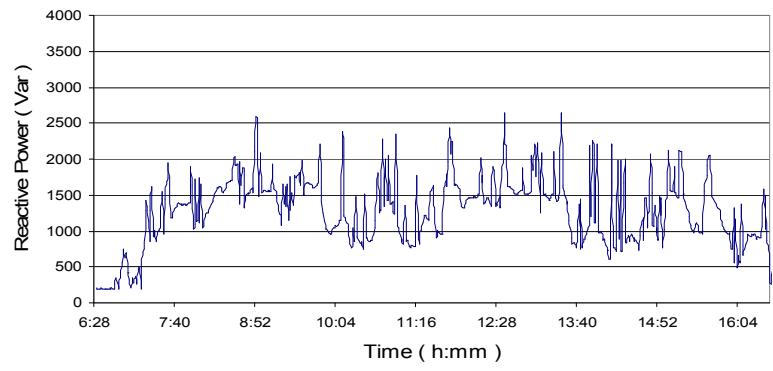

Fig. 3(d). Reactive Power produced for a low solar irradiance day

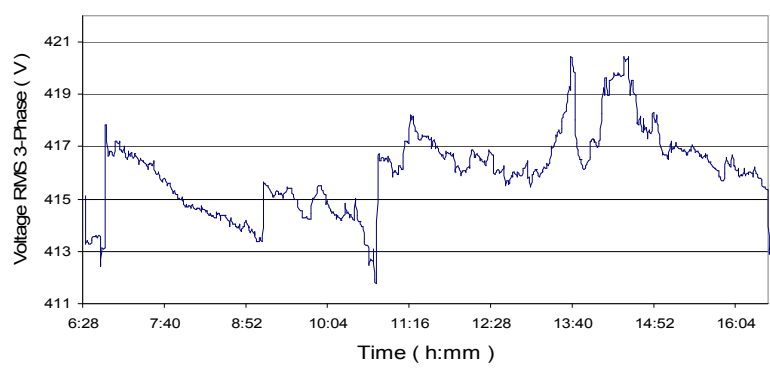

Fig. 3(e). RMS Voltage (3-Phase) measured for a low solar irradiance day 


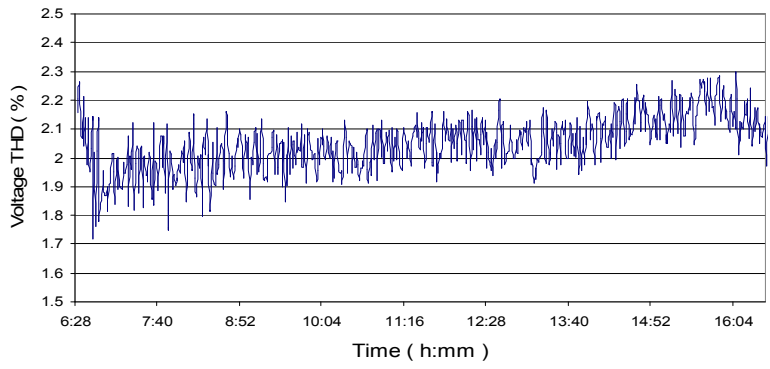

Fig. 3(f). Voltage THD measured for a low solar irradiance day

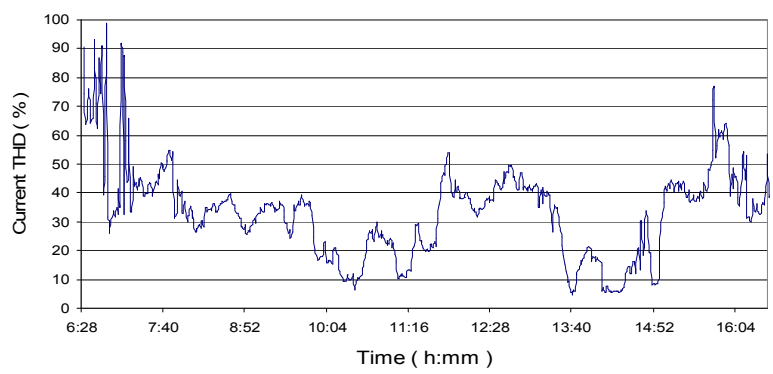

Fig. 3(g). Current THD measured for a low solar irradiance day

Fig. 3. Power Quality Measurements for a low solar irradiance day

Low solar irradiance (Fig. 3(a)) can dramatically affect the output of the photovoltaic system as depicted in Fig. 3(b). The active power production becomes comparable to reactive power production (Fig. 3(c)) maintaining the power factor to very low levels (Fig. 3(d)). The RMS voltage (3-Phase) has small range limits (Fig. 3(e)) for the case of low irradiance, as previously observed for the case of average irradiance. The system injects a highly distorted current (with respect to the fundamental frequency current) to the distribution network during low solar irradiance conditions as shown in Fig. 3(g). Both voltage and current total harmonic distortion are above the acceptable limits of the standard EN 61727 (Fig. 3(f) and Fig. 3(g)).

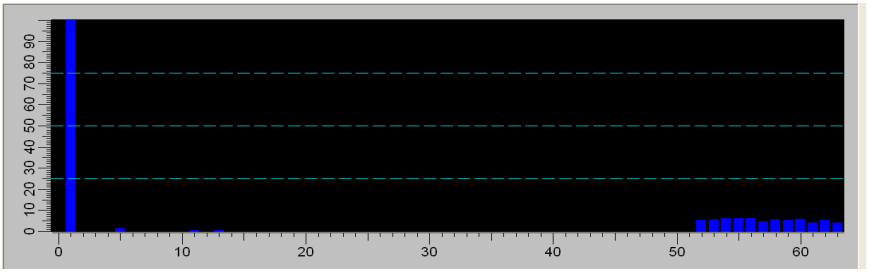

Fig. 4(a). Voltage Harmonic Spectrum at low solar irradiance

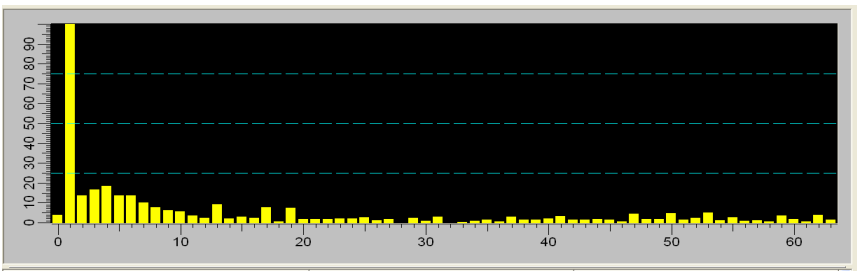

Fig. 4(b). Current Harmonic Spectrum at low solar irradiance

Fig. 4. Frequency Spectrum at low solar irradiance conditions

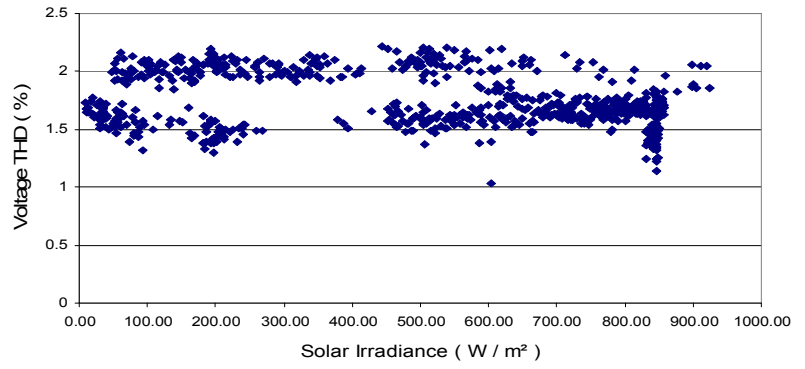

Fig. 5(a). Voltage THD vs Solar Irradiance

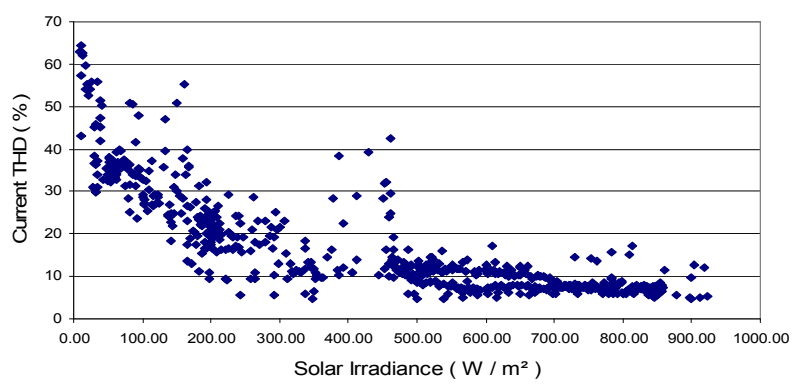

Fig. 5(b). Current THD vs Solar Irradiance

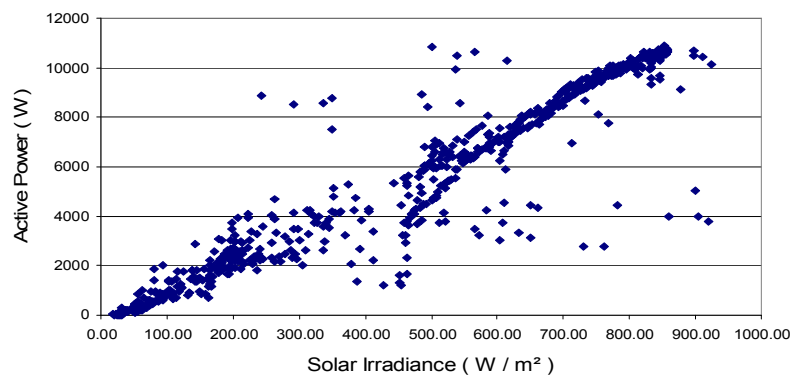

Fig. 5(c). Active Power vs Solar Irradiance

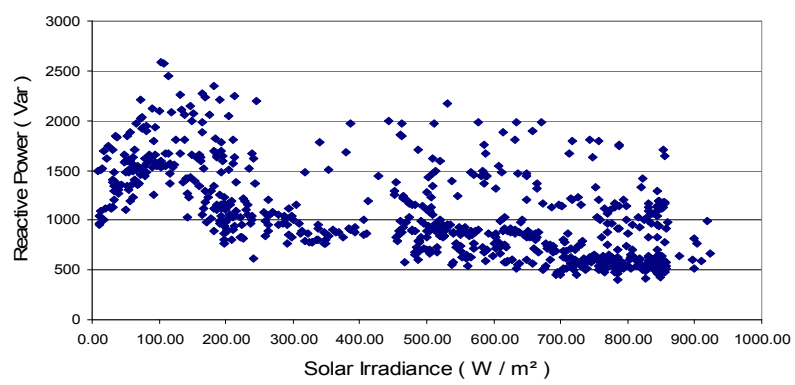

Fig. 5(d). Reactive Power vs Solar Irradiance

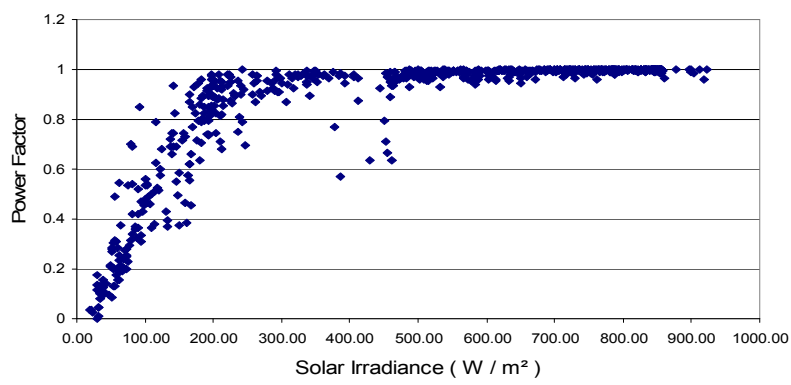

Fig. 5(e). Power Factor vs Solar Irradiance

Fig. 5. Power Quality Measurements versus Solar Irradiance 
The spectrum of the voltage and current waveforms for the low irradiance case are shown in Fig 4(a) and 4(b) respectively. Distortion can be divided into low and highorder harmonic regions of the frequency spectrum as shown in Fig. 4(a). High-order harmonic distortion is mainly associated with the inverter switching mechanism operation [16].

In the last part, power quality quantities were correlated with instantaneous solar irradiance measured during a two week period and the results are shown in Fig. 5(a) - 5(e). The Voltage and Current THD are shown in Fig. 5(a) and Fig. 5(b) respectively, and the results confirm the high harmonic content in the current waveform. The total voltage harmonic distortion measured at the output of the system is not strongly dependent on the fluctuations of solar irradiance (Fig. 5(a)), but the current harmonics, on the other hand, are very sensitive to changes of incident radiation. The total voltage harmonic distortion ranges from $1.5 \%$ to $2.2 \%$, confirming the existence of an accurate control mechanism for voltage as shown in Fig. 5(a). The current total harmonic distortion has a larger range of values, from $6 \%$ to $65 \%$ (Fig. 5(b)). The active power delivered to the distribution network has been found to vary linearly with changes of the solar irradiance incident on the PV modules as shown in Fig. 5(c). In contrast, the reactive power produced depends non-linearly on solar irradiance having higher values at low solar irradiance (Fig. 5(d)). Finally, the power factor behaviour due to changes of solar irradiance is shown in Fig. 5(e). The power factor acts linearly for values of solar irradiance lower than $200 \mathrm{~W} / \mathrm{m}^{2}$ and stays close to unity for higher values. The results for active power, power factor and total current harmonic distortion shown above are in good agreement with results presented in [17], [18].

\section{Conclusion}

In this paper, results from power quality observations obtained at a grid connected PV site consisting of 14 different PV systems, have been presented. Measurements from the grid connected PV site under test have been analyzed and evaluated to observe the overall effect of solar irradiance on the operation of the grid connected systems under test. Results for two different scenarios have been considered, namely, "average" and "low" irradiance and the effect of the solar irradiance on the power quality measurements has been investigated. It has been found that low solar irradiance has a significant impact on the power quality of the output of the PV system.

\section{Acknowledgement}

The authors would like to acknowledge the financial support provided by the Institute of Physical Electronics, University of Stuttgart, Germany and the Cyprus Research Promotion Foundation.

\section{References}

[1] http://www.who.int/mediacentre/factsheets/fs266/en/

[2] M. Roscia, D. Zaninelli, "Sustainability and Quality Through Solar Electric Energy", $10^{\text {th }}$ International Conference on Harmonics and Quality of Power, Vol. 2, pp. 782 - 787, 2002.

[3] T. Tomita, "Toward Giga-Watt Production of Silicon Photovoltaic Cells, Modules and Systems", 31 th IEEE Photovoltaic Specialists Conference, pp. 7 - 11, January 2005.

[4] P. P. Barker, "Advances in Solar Photovoltaic Technology: An Applications Perspective", IEEE Power Engineering Society Summer Meeting, San Francisco, Vol. 2, pp. 1955 1960, June 2004.

[5] F. L. Albuquerque, A. J. Moracs, G. C. Guimaracs, S. M. R. Sanhueza, A. R. Vaz, " Optimization of a Photovoltaic System Connected to Electric Power Grid", IEEE/PES Transmission \& Distribution Conference \& Exposition, Latin America, pp. 645 - 650, November 2004.

[6] P. Boulanger, P. Malbranche, "Photovoltaic system performance statistical analysis", $3^{\text {rd }}$ World Conference on Photovoltaic Energy Conversion, Vol. 2, pp. 2098 - 2101, May 2003.

[7] P.A. Hutchinson, A.B. Reyes, C. M. Whitaker, D.E. Collier, D.D. Whitney, D.E. Osborn, “ PVUSA's small system test center", $26^{\text {th }}$ IEEE Photovoltaic Specialists Conference, pp. 1353 - 1356, 29 September - 3 October 1997.

[8] R. Gonzalez, H. R. J imenez, J. M. Huacuz, "Voltage and Power Ratio Effects of Grid-Connected PV Plant's Operation on the Performance Ratio and Total System Efficiency", 3rd International Conference on Electrical and Electronics Engineering, pp. 1 - 4, September 2006.

[9] P. J. M. Heskes, J. H. R. Eslin, "Power Quality Behaviour of Different Photovoltaic Inverter Topologies", $24^{\text {th }}$ International Conference, Nurnberg, Germany, pp. 9, May 2003.

[10] J. Balcells, J. Dolezal, J. Tlustý, V. Valouch , "Impacts of Renewable Sources on Power Quality in Distribution Systems", ICEREPQ 04, Barcelona, pp. 5, 31 March - 2 April 2004.

[11] Shih-An Yin, Chun-Lien Su, Rung-Fang Chang, "Assessment of Power Quality Cost for High Tech Industry", Power India IEEE Conference, pp. 6, April 2006.

[12] EN 50160 "Voltage characteristics of electricity supplied by public distribution systems".

[13] R. C. Dugan, M. F. McGranaghan, S. Santoso, H. W. Beaty, "Electrical Power Systems Quality", Second Edition, McGraw-Hill.

[14] M. Aiello, A. Catalioti, S. Favuzza, G. Graditi, "Theoretical and Experimental Comparison of Total Harmonic Distortion Factors for the evaluation of Harmonic and Interharmonic Pollution of Grid-Connected Photovoltaic Systems", IEEE Transactions on Power Delivery, Vol. 21, No. 3, pp. 1390 1397, July 2006.

[15] H. Muller, A. Rudolf, G. Aumayr, "Studies of Distributed Energy Supply Systems using an Innovative Energy Management System", 22nd IEEE Power Engineering Society International Conference on Power Industry Computer Applications (Innovative Computing for Power Electric Energy Meets the Market), pp. 87-90, May 2001.

[16] T. Abeyasekera, C. M. Johnson, D. J. Atkinson and M. Armstrong, "Suppression of Line Voltage Related Distortion 
in Current Controlled Grid Connected Inverters", IEEE Transactions on Power Electronics, Vol. 20, No. 6, pp. 13931401, November 2005.

[17] G. J. Yu, J. H. So, Y. S. Jung, G. H. Kang, "Performance results of $15 \mathrm{KW}$ BIPV sunshade system" $31^{\text {th }}$ IEEE Photovoltaic Specialists Conference, pp. 1722 - 1725, January 2005.

[18] D. Chenvidhya, J. Thongporn, U. Sangpanich, N. Wongyao, K. Kirtikara and C. Jivacate, "A Thai national demostration project on PV grid-interactive systems: Power quality observation", Proceedings of 3rd World Conference on Photovoltaic Energy Conversion, Vol. 3, pp. 2152 - 2154, May 2003.

\section{Biographies}

Minas Patsalides is currently working on a joint project on power quality which is a collaboration between the University of Cyprus and the Electricity Authority of Cyprus. Minas has obtained the top mark of his year from the Department of Electrical and Computer Engineering, University of Cyprus. His research interests include measurements and analysis of power quality events, renewable sources of energy and applications of ArcGis Systems in the evaluation of measurements of electromagnetic fields.

Demetres Evagorou received the BEng in Electrical and Electronic Engineering, and the MSc in Communications and Signal Processing from Imperial College in 2000 and 2001 respectively. He worked for four years as an analyst systems engineer and he is currently a $\mathrm{PhD}$ student at the University of Cyprus, Department of Electrical and Computer Engineering. His research interests include signal processing techniques.

George Makrides received the BEng in Electrical and Electronic Engineering from Queen Mary University of London in 2003. He continued his studies obtaining the MPhil degree in Engineering from the University of Cambridge and graduated in 2004. He worked for two years as a radio network engineer in one of the telecommunication operators of Cyprus and is currently a $\mathrm{PhD}$ student at the University of Cyprus, Department of Electrical and Computer Engineering. His research interests include photovoltaic systems, measurement and analysis of power frequency electric and magnetic fields.

Zenon Achillides is from Nicosia, Cyprus. He received the Diploma of Technician Engineer from the Higher Technical Institute in Nicosia, Cyprus in 1988 the B.Eng. degree from Brunel University in 1992, and the M.Sc. degree from UMIST in 1993. He has been working in the Electricity Authority of Cyprus (EAC) since 1994 and he is currently a Ph.D. student at the Department of Electrical and Computer Engineering, University of Cyprus. His research interests include the breakdown of voids in electric power cables, signal-processing techniques applied to power engineering, and renewable energy sources.

George E. Georghiou is currently an Assistant Professor at the Department of Electrical and Computer Engineering, University of Cyprus. Prior to this, he was the undergraduate course leader in Electrical Engineering at the University of Southampton, Department of Electronics and Computer Science and a Research Advisor for the Energy Utilisation, University of Cambridge.
Having graduated from the University of Cambridge with a BA, MA, MEng and PhD (1999), Dr Georghiou continued his work at the University of Cambridge in the capacity of a Fellow at Emmanuel College for a further three years (1999-2002). His research interests lie predominantly in the utilization of electromagnetic fields and plasma processes for environmental, biomedical applications, BioMEMS, Nanotechnology and Power Systems. Dr Georghiou has also a special interest in the area of renewable sources of energy.

Andreas Stavrou received his BSc and MSc degrees from Leningrad State Technical University, USSR in 1988 and 1990 respectively and his $\mathrm{PhD}$ degree from Aberdeen University, Scotland in 1995. He joined the Electricity Authority of Cyprus, South East Area in 1996. Until 1997 he worked in the Underground Cables Department and after that he spent three years in the Planning Department. $\mathrm{He}$ is currently in the Transmission Substations Construction and Maintenance department in the South East Area. He is involved in the Installation, testing commissioning and maintenance of high and medium voltage switchgear, transformers, protection relays and SCADA.

Andreas Stavrou is a Member of IEEE and a reviewer of IEEE Power Engineering Society publications. He has several publications in refereed journals and conferences on electrical machines and condition monitoring issues.

Venizelos Efthimiou received his BSc in Electrical Engineering \& Electronics, MSc in Power Systems, and PhD in Transmission Lines \& Transformers degrees from the University of Manchester Institute of Science and Technology, in 1975, 1976 and 1979 respectively. He joined the Electricity Authority of Cyprus in 1979 where he is currently employed. He has been involved in major projects in the EAC and he has several publications in refereed journals and conferences in the field of power transmission.

Bastian Zinsser received his undergraduate degree from the Institute of Physical Electronics (ipe) at the University of Stuttgart and is currently a PhD student at the same Institute in the field of Photovoltaic Systems. His research interests lie in the areas of grid connected photovoltaic systems, PV system modelling and analysis.

Wolfgang Schmitt received his $\mathrm{PhD}$ degree from the Ecole Supérieure d'Electricité (SUPELEC) / Université de Paris XI, France in the area of Technico-economic sizing of photovoltaic hybrid energy systems. He is currently the group leader of the "Systems group" of the Institute of Physical Electronics (ipe) at the University of Stuttgart. His research interests occupy the areas of grid connected photovoltaic systems, photovoltaic hybrid systems, power electronics especially for photovoltaic applications, system modelling and system optimisation.

Jürgen H. Werner is currently the Director of the Institute of Physical Electronics (IPE) at the University of Stuttgart and widely accepted as a pioneer in the field of PV. He earned his diploma degree in 1979 from the University of Tübingen and received his Ph.D. from the University of Stuttgart in 1983. His $\mathrm{PhD}$ thesis work on grain boundaries in silicon at the MaxPlanck-Institute for Solid State Research, received the Otto-HahnMedal of the Max-Planck-Society, in recognition for the quality of his work. Between 1985-1987 he spent two years in the United 
States as a guest scientist at the IBM T. J. Watson Research Center and AT\&T Bell Laboratories, Murry Hill, working on Schottky diodes. In 1987 he was offered a position as a permanent scientist at the Max-Planck-Society and in 1991 he received the habilitation from the University of Munich. During these years, his research concentrated on semiconductor interfaces. In 1996 he became the director and full professor of the Institute for Physical Electronics. Prof. Werner is author and co-author of over 230 publications, the editor of nine books and has more than 30 invited papers at prestigious international conferences. 